\title{
The Sixth Vital Sign: Body Mass Index in Patients With Sickle Cell Disease
}

\author{
Samir K. Ballas
}

\section{To the Editor}

Survival of patients with sickle cell disease (SCD) in general and sickle cell anemia in particular has increased significantly over the past 40 years. The advent of preventative measures and new therapies has contributed to the increasing longevity of patients with SCD. Recent publications described patients with SCD in their sixth, seventh or eighth decade [1].

As patients with SCD age, they become vulnerable for developing comorbidities that were not previously seen or were rare in this cohort of patients. Thus, the advances in prevention and management may be offset by the increasing incidence of comorbidities associated with aging. This letter focuses on obesity as a comorbidity in SCD.

Obesity is a serious epidemic in the USA both in children and adults [2]. Obesity is associated with or a risk factor for other diseases including, but not limited to, type 2 diabetes, hypertension, sleep apnea, cardiovascular disease, osteoarthritis, etc. These diseases, in turn, worsen the clinical picture of SCD and increase the frequency of vaso-occlusive crises (VOCs) and other complications of SCD, thus creating a vicious cycle.

Obesity is diagnosed by the determination of the body mass index (BMI) which is calculated by dividing the body weight in $\mathrm{kg}$ by the height in meters squared: $\mathrm{BMI}=\mathrm{kg} / \mathrm{m}^{2}$. The World Health Organization (WHO) classified BMI into five classes as follows: normal (18.5 - 24.9), overweight (25.0 - 29.9), obese class I (30.0 - 34.9), obese class II (35.0 - 39.9), and obese class III $(>40.0)$. Survival was reported to be directly related to the BMI [3].

The prevalence of obesity in patients with SCD seems to be on the increase [4]. We have compared the BMI of some of our patients when first seen in the steady state and five or more years later as shown in Table 1. There was a surprisingly significant increase in the BMI especially in women with hemoglobin SCD. Accordingly we recommend that the BMI should be routinely determined as a sixth vital sign in addition to temperature, respiratory rate, heart rate, blood pressure, and pain scale in all patients with SCD.

The best approach to manage obesity in patients with SCD is to follow the recommendations of the US Preventive Task Force (USPSTF) [5]. Providers should screen all adult patients for obesity and refer patients with BMI > 30 to multicomponent interventions. Dietary management entails the determination of the daily calorie requirement for each patient best determined by a nutritionist. Bariatric surgery may be considered if dietary management fails.

\section{Conflicts of Interest}

The author claims no conflicts of interest.

\section{References}

1. Ballas SK, Pulte ED, Lobo C, Riddick-Burden G. Case series of octogenarians with sickle cell disease. Blood. 2016; 128:2367-2369.

2. Ogden CL, Carroll MD, Kit BK, Flegal KM. Prevalence of childhood and adult obesity in the United States, 20112012. JAMA. 2014;311(8):806-814.

3. Manson JE, Stampfer MJ, Hennekens CH, Willett WC. Body weight and longevity. A reassessment. JAMA. 1987;257(3):353-358.

4. Woods KF, Ramsey LT, Callahan LA, Mensah GA, Litaker MS, Kutlar A, Barbeau P, et al. Body composition in women with sickle cell disease. Ethn Dis. 2001;11(1):3035.

5. Stephenson J. USPSTF: Lifestyle counseling advised for overweight, obese adults with other cardiovascular risk factors. JAMA. 2014;312(11):1085.

Manuscript submitted July 18, 2017, accepted July 31, 2017

Cardeza Foundation for Hematologic Research, Department of Medicine, Sidney Kimmel Medical College, Thomas Jefferson University, 1020 Locust Street, Suite 394, Philadelphia, PA 19107, USA.

Email: samir.ballas@jefferson.edu 
Table 1. Age and Body Mass Index in Patients With Sickle Cell Disease

\begin{tabular}{|c|c|c|c|}
\hline Patient & Diagnosis & Age (years)/sex & BMI \\
\hline \multirow[t]{2}{*}{ A } & $\mathrm{Hb} \mathrm{SC}$ & $19 / \mathrm{F}$ & 27.1 \\
\hline & & $47 / F$ & 44.5 \\
\hline \multirow[t]{2}{*}{ B } & $\mathrm{Hb} \mathrm{SC}$ & $23 / \mathrm{F}$ & 16.1 \\
\hline & & $45 / \mathrm{F}$ & 28.5 \\
\hline \multirow[t]{2}{*}{$\mathrm{C}$} & SS & $23 / \mathrm{F}$ & 27.0 \\
\hline & & $31 / \mathrm{F}$ & 37.9 \\
\hline \multirow[t]{2}{*}{$\mathrm{D}$} & SS & $31 / \mathrm{F}$ & 26.6 \\
\hline & & $42 / \mathrm{F}$ & 28.5 \\
\hline \multirow[t]{2}{*}{ E } & $\mathrm{Hb} \mathrm{SC}$ & $25 / \mathrm{F}$ & 24.3 \\
\hline & & $40 / F$ & 28.2 \\
\hline \multirow[t]{2}{*}{$\mathrm{F}$} & SS & 19/M & 21.8 \\
\hline & & $44 / \mathrm{M}$ & 28.8 \\
\hline
\end{tabular}

F: female; Hb: hemoglobin; M: male; SS: sickle cell anemia. 